\title{
Processing technologies of $\mathrm{Ni}-\mathrm{Ti}$ based shape memory alloys
}

\author{
I. Szurman a, and M. Kursa \\ ${ }^{1}$ VSB-Technical University of Ostrava, Ostrava, Czech Republic
}

\begin{abstract}
Transformation characteristics and properties of the Ni-Ti based shape memory alloys are in the first place highly dependent on processing technology. It is known that small deviation from the required composition can cause very important change of transformation temperatures. For this reason it is necessary to pay special attention to the metallurgy of these alloys. The current key technologies for processing are in most cases realised in vacuum, and various methods of melting are used (electron-beam melting, arc melting, induction highfrequency melting). Plasma melting is another possibility. Complications during preparation are caused mainly by carbon, nitrogen and oxygen, which form non-metallic inclusions. Carbon is related to the alloys mainly in the course of their preparation in graphite crucibles. Other problems are connected with observation of appropriate conditions for crystallisation and with related minimisation of possible micro- and macro-segregations. Formation of titanium carbide and titanium oxide in Ni-Ti shifts concentration of individual elements and thus leads also to change of the temperature of martensitic transformation. Creation of a low-melting phase $\mathrm{Ti}_{2} \mathrm{Ni}$, which causes a distinct susceptibility to hot formation of cracks, is another issue arising during melting of Ni-Ti alloys. The presented article is focused on comparison of individual methods of preparation of the alloys mentioned above, i.e. induction vacuum melting, plasma and electron-beam melting.
\end{abstract}

\section{Introduction}

Big attention is at present being paid to the conditions of preparation of materials. This obviously concerns also the Ni-Ti-Me based alloys. Phenomenon of shape memory was observed for the first time in an equi-atomic intermetallic compound of TiNi in 1963 [1]. Ni-Ti based alloys are highly sensitive to stoichiometry. A deviation of 0.1 at. $\%$ from the required composition can change here transformation temperature even by $10 \mathrm{~K}$. The alloys alloyed by other elements have this concentration dependence of temperature of martensitic transformation lower. However, in these ternary or quaternary alloys different transformation sequences occur in comparison with binary alloys. These multi-component systems generate also weaker forces at transformation $[2,3]$.

The present key technologies for preparation of $\mathrm{Ni}-\mathrm{Ti}$ and Ni-Ti-Me alloys are realised mostly in vacuum. They use various methods of melting (electron-beam melting, arc melting [4, 5], induction high-frequency melting in vacuum in a graphite crucible $[6,7,8]$ ). Plasma melting is another possibility. Typical raw materials for preparation of Ni-Ti based alloys are titanium sponge and metallic nickel. Ni has usually lower contents of interstitial impurities. On the other hand titanium sponge can contain even 400-800 ppm of oxygen and 25-80 ppm of carbon. Typical superelastic nitinols contain 350-500 ppm of oxygen and 100-500 ppm of carbon. These data naturally depend on input materials and used technology of preparation. It is possible to describe $\mathrm{Ni}-\mathrm{Ti}$ alloys as super-clean, if they contain $<100 \mathrm{ppm}$ of oxygen and $<20 \mathrm{ppm}$ of carbon. Such alloys are usually prepared by high-frequency induction vacuum melting in graphite crucible combined with re-melting in a vacuum arc furnace [9].

Preparation of highly pure and special alloys, to which shape memory Ni-Ti based alloys undoubtedly belong, by plasma metallurgy requires use of defined controlled atmospheres. It is necessary to ensure high purity of inert gases. The most commonly used gas in plasma metallurgy is argon. It is used for stabilisation of the arc discharge of plasma burners. it is a medium for heat transfer to re-heated material and it forms after decomposition of low-temperature plasma also a protective working atmosphere in a plasma furnace $[10,11]$.

a

e-mail: ivo.szurman@vsb.cz

This is an Open Access article distributed under the terms of the Creative Commons Attribution-Noncommercial License (http://creativecommons.org/licenses/by-nc/3.0/), which permits unrestricted use, distribution, and reproduction in any noncommercial medium, provided the original work is properly cited. 
Appropriate arrangement of charge in the crucible is also very important at vacuum high-frequency induction melting $[12,13]$. It was established that if the surface of the crucible is covered with Ti disks, the content of carbon in produced alloy is reduced in comparison with the case of random arrangement of the charge. This phenomenon is caused by formation of a TiC layer, which acts as a diffusion barrier. It was found that absorption of carbon is strongly dependent on temperature. Extensive experiments concerning preparation of alloys in a graphite crucible were carried out. It was established that with increasing time of dwell of the melt in the crucible the melt gets enriched in carbon. Increase of carbon contents occurs also at increase of temperature of melting. Oxygen penetrates into material at melting in a graphite crucible particularly form input raw materials, or from furnace atmosphere [14].

In the case of preparation of an alloy by electron-beam melting a contamination of the alloy by carbon is prevented thanks melting of material in a vertical arrangement of uplift. Electron furnace operates on the principle of zone melting. Input material consists of an ingot prepared in a vacuum induction furnace. Content of carbon is usually $4-10 x$ lower than at the VIM technology. Content of oxygen is usually very low due to working vacuum, which in this case achieves $10^{-2} \mathrm{~Pa}$ as compared with $10 \mathrm{~Pa}$ at vacuum induction melting. Contamination by oxygen therefore depends mainly on purity of the input material. Drawback of this technology consists in control of chemical composition. This issue is caused by possible evaporation of the alloy components. Another drawback is small volume of the alloy, so it can be stated that this technology is not suitable for commercial use [15]. Objective of this procedure was to reduce content of gases and carbon in an alloy.

\section{Experiment}

Two alloys were chosen for experiment: A (Ni50.6 - Ti49.4 at. \%) and B (Ni49.8 - Ti42.2 - Zr8 at. \%). Preparation of alloys was made with use of plasma melting, vacuum induction melting in a graphite crucible and melting by electron beam in vacuum. The following input materials were chosen for preparation of alloys. $\mathrm{Ni}$ cathodes $4 \mathrm{~N}$ (impurities - $\mathrm{C} 0.01 \%$, Fe $0.0048 \%, \mathrm{Al}<0.0002 \%$, Ti $0.0056 \%, \mathrm{O}_{2} 0.002 \%, \mathrm{~N}_{2} 0.0002 \%$ ), formed $\mathrm{Ti}-2 \mathrm{~N} 8$ (impurities - $\mathrm{C} 0.025 \%$, Fe $0.016 \%, \mathrm{Al}<0.002 \%, \mathrm{Ni} 0.051 \%, \mathrm{O}_{2} 0.0061 \%, \mathrm{~N}_{2} 0.0002 \%$ ), $\mathrm{Zr}$ wire, diameter $2.0 \mathrm{~mm}$, purity $99.2 \%, \mathrm{C}-0.0041 \%$, O $0.0031 \%$ ). All the input materials were thoroughly cleaned mechanically and chemically before melting. For the purposes of metallographic testing the samples were abraded with paper containing abrasive material $\mathrm{SiC}$, polished by water suspension of $\mathrm{Al}_{2} \mathrm{O}_{3}$. Microstructure was developed by an etching agent $1 \mathrm{HF}: 4 \mathrm{HNO}_{3}: 5 \mathrm{H}_{2} \mathrm{O}$, observation of micro-structure and taking pictures of it was made on the microscope Olympus GX51 equipped with the camera DP12. Determination of quantity of gases was made by thermo-evolution method on the instrument LECO TC436. Content of carbon was determined by spectrometry with use of the instrument SpectroMaxx.

\subsection{Plasma melting}

Material is placed at plasma melting in a copper, water cooled, mould, which is dragged by a screw under the plasma burner. The mould can be used for melting of materials with $\mathrm{T}_{\mathrm{M}}<3400^{\circ} \mathrm{C}$. The heat necessary for melting of metal is generated by the plasma burner. Temperature of plasma achieves at this method of melting $6500 \mathrm{~K}$. The gas Ar 4N6 was used as a plasma forming gas. Parameters of melting were the following: flow $\mathrm{Ar}-$ $271 . \mathrm{min}^{-1}$, input power $30 \mathrm{~kW}$, rate of feed of the mould was $2 \mathrm{~cm} \cdot \mathrm{min}^{-1}$. In this manner the ingots with mass $200-1000 \mathrm{~g}$ were prepared, in dependence of the type of the mould. Micro-structures of the prepared alloys are shown in figures 1-2. After preparation the gases $\left(\mathrm{N}_{2}\right.$ and $\left.\mathrm{O}_{2}\right)$ and also $\mathrm{C}$ were determined in material. Results are presented in Table 1. 


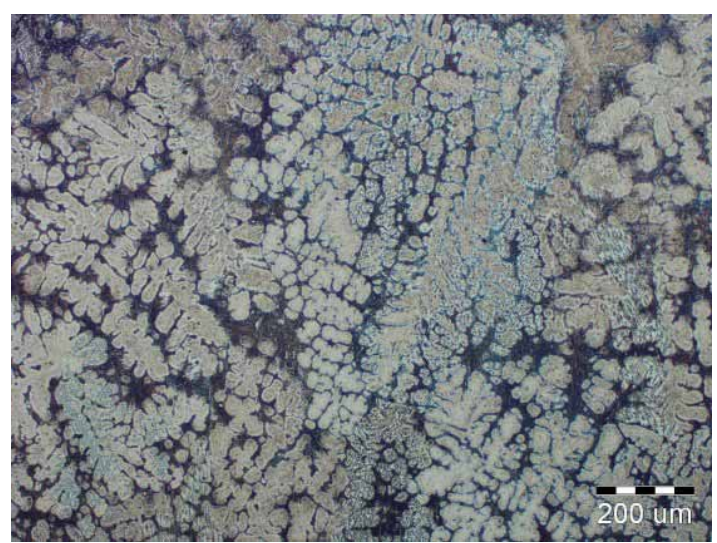

Fig. 1. Alloy A, plasma melting, 100x, OM

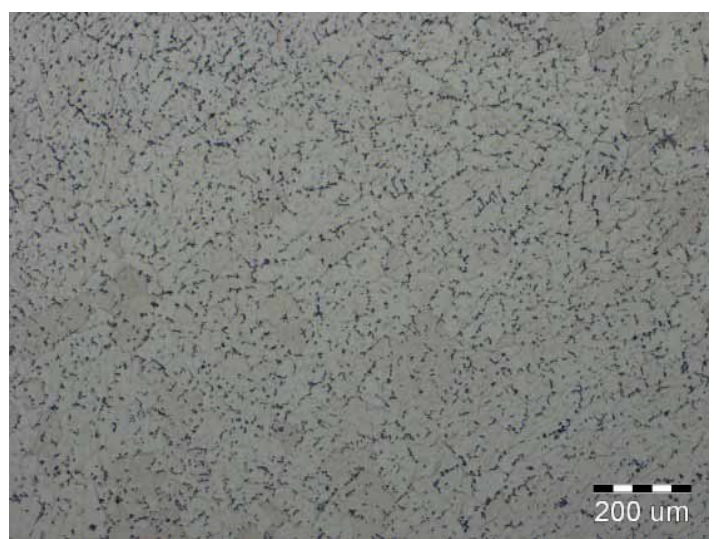

Fig. 2. Alloy B, plasma melting, 100x, OM

\subsection{High frequency induction melting in vacuum}

Vacuum induction melting was made in the furnace Leybold Heraeus IS1/FFF, equipped with a three stage rotary pump. Well proven graphite crucible was used for vacuum melting. Prior to melting itself a flushing melting was made with use of binary Ni-Ti alloy in order to create a TiC layer, the purpose of which was explained above. A separate crucible was used for each alloy. Material was also appropriately arranged in the crucible. Melting was realised under the following parameters. First, the furnace was evacuated to a low residual pressure and then filled with $\operatorname{Ar}(6 \mathrm{~N})$. Afterwards the furnace was evacuated. Input power of the furnace was approx. $15 \mathrm{~kW}$. This was followed by filling the furnace with $\operatorname{Ar}(6 \mathrm{~N})$ to a pressure of several $\mathrm{kPa}$ and casting of material into a ingot-mould with diameter of $10 \mathrm{~mm}$, height $300 \mathrm{~mm}$. Mass of the ingot was $200 \mathrm{~g}$. Microstructures of the prepared alloys are shown in figures 3-4. The preparation was also followed by determination of gases $\left(\mathrm{N}_{2}\right.$ a $\left.\mathrm{O}_{2}\right)$ and of $\mathrm{C}$ in material. Results are presented in Table 1 .

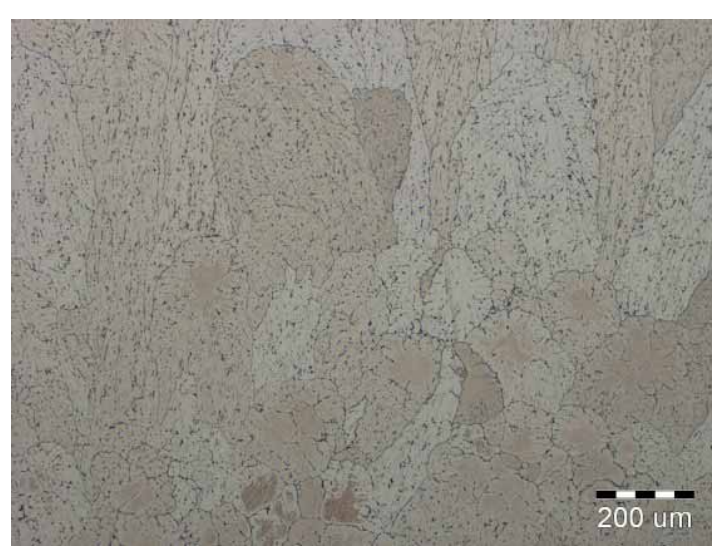

Fig. 3. Alloy A, induction melting, 100x, OM

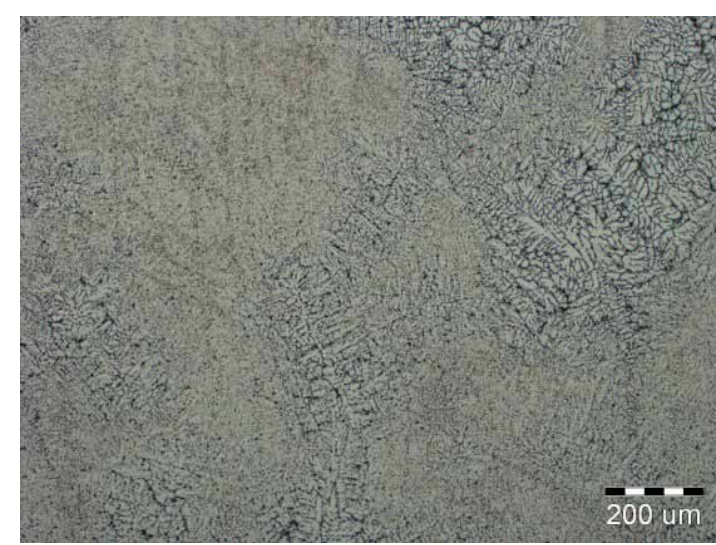

Fig. 4. Alloy B, induction melting, 100x, OM

\subsection{Electron-beam melting}

Used electron furnace works on the principle of vertical zone melting with floating zone. For melting in the electron furnace an ingot was used, which was prepared in high frequency induction vacuum furnace. Preparation of the ingot was realised in full compliance with the chapter 2.2. Ingot surface was abraded and etched by HF. Melting was realised under pressure of $8.10^{-3} \mathrm{~Pa}$. Voltage was $6.4 \mathrm{kV}$, current $28 \mathrm{~mA}$. Rate of feed of the zone was $3 \mathrm{~mm} \cdot \mathrm{min}^{-1}$. During melting a slag appeared on the surface of the bar. Micro-structure of the alloy after electron-beam melting is shown in figure 5 . 


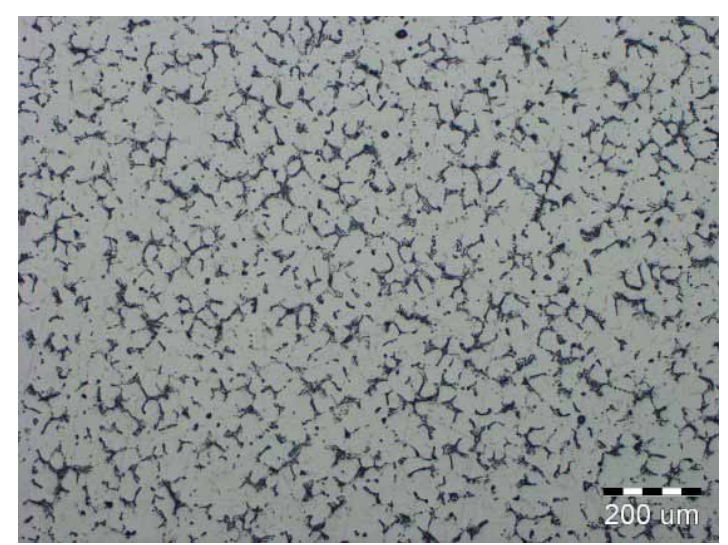

Fig. 5. Alloy A, electron beam melting, 100x, OM

Table. 1 Contents of interstitial elements in alloys.

\begin{tabular}{|c|c|c|c|c|}
\hline alloy & melting & $\begin{array}{c}\text { oxygen } \\
\text { [wt. \%] }\end{array}$ & $\begin{array}{c}\text { nitrogen } \\
\text { [wt. \%] }\end{array}$ & $\begin{array}{c}\text { carbon } \\
\text { [wt. \%] }\end{array}$ \\
\hline \multirow{3}{*}{ A } & plasma & 0.0970 & 0.0155 & 0.019 \\
\cline { 2 - 5 } & vacuum & 0.0651 & 0.0410 & 0.039 \\
\cline { 2 - 5 } & $\begin{array}{c}\text { electron } \\
\text { beam }\end{array}$ & 0.0857 & 0.0420 & 0.020 \\
\hline \multirow{2}{*}{ B } & plasma & 0.1042 & 0.0144 & 0.017 \\
\cline { 2 - 5 } & vacuum & 0.0818 & 0.0037 & 0.037 \\
\hline
\end{tabular}

\section{Discussion of the obtained results}

The performed experiments revealed that technology of plasma melting for preparation of the Ni-Ti and Ni-TiMe based alloys has its advantages, but also some drawbacks. The alloys prepared by this method contain usually considerable amount of gases (oxygen and nitrogen - see tab. 1). There is no danger of carbon contamination from material of crucible. The key drawbacks comprise high non-homogeneity with unsatisfactory distribution of alloying elements, as well as their unsuitable shape forming operations resulting from the shape of the mould. This technology was not found to be the most suitable for preparation of the above mentioned alloys due to the necessity of the following operation - high frequency induction re-melting and casting of material into a mould (usually bar), suitable for the following forming operations. From the viewpoint of micro-structure the alloys prepared in a plasma furnace are usually highly non-homogenous, which is documented namely by the fig. 1 .

Melting in induction furnace in a graphite crucible approved itself at preparation of these materials. Longer dwell of the melt in crucible leads to high carbon pick up of the alloy. For this reason the dwell was reduced to a minimum. From the viewpoint of micro-structure the alloys are significantly more homogenous (Figs. 3-4) than alloys from plasma furnace (Fig. 1). It is possible to see very well on the ingot cross-section characteristic microstructure, related to heat outlet from the ingot-mould during cooling. Crystals are laid in direction of heat outlet. For preparation of alloys with satisfactory low content of oxygen and nitrogen it is necessary to use available raw materials with the lowest possible content of gases, and also high purity argon with purity at least $6 \mathrm{~N}$. The alloys melted in a graphite crucible contain very often carbidic phase of the type TiC.

Microstructure of the alloy A after electron-beam melting can be characterised as cellular. Microstructure is at all places of cross section almost identical. In this case too (similarly as in the case of plasma melting), this technique cannot be fully recommended. In this case, however, it is necessary to supply at first the input material in the form of an ingot prepared in high frequency induction vacuum furnace.

From the viewpoint of content of gases the best results were obtained at melting in induction vacuum furnace. In the alloy from electron furnace, where we expected reduction of content of gases, this in fact did not happen. This fact probably corresponds with the observed slag formation during melting. It will be necessary to further verify this method. In plasma furnace a gas Ar $4 \mathrm{~N} 6$ was used. Use of Ar of higher purity ( $6 \mathrm{~N}$ as compared to 4N6) could ensure reduction of content of gases in alloys. 
From the viewpoint of carbon content the best situation was, as it could have been expected, after plasma melting. The biggest carbon content was found, again as expected, in the alloys prepared in high frequency induction vacuum furnace in a graphite crucible. In this case carbon is usually bound in the form of TiC. In case of the electron-beam melting the initial carbon content from induction re-melted ingot was also reduced. The obtained quantity of carbon can be estimated as satisfactory.

\section{Conclusions}

Two types of alloys were prepared (binary and ternary). Plasma furnace, high-frequency induction vacuum furnace and electron furnace were used as melting units. After evaluation of experiments it was established that microstructures of alloys after plasma melting were highly non-homogenous, but carbon content was much lower than in the alloys prepared by other methods. The question of gas contents is in this case also arguable. In the case of electron-beam melting the advantage of use of this method for reduction of gas content was not confirmed. Carbon content is here satisfactory. Preparation of alloys in high frequency induction vacuum furnace in combination with casting of the alloy into graphite moulds seems to be the most suitable method due to the fact that material of satisfactory characteristics for the needs for forming can be prepared just by one melting operation.

\section{Acknowledgement}

The presented results were obtained within the frame of solution of the research project MSM 6198910013 „Processes of preparation and properties of high-purity and structurally defined special materials“", and grant project GA6379211/2201 „Optimisation of chemical composition, structural characteristics, mechanical properties of NiTi alloys for biomechanical applications".

\section{References}

[1] GILFRICH, J.W., WILEY R.C.: J. Appl. Phys., 34, 1473 (1963)

[2] PACHOLEK, P.: Materiálově inženýrské charakteristiky vratného tvarově pamětového jevu v materiálech na bázi TiNi [Material-engineering characteristics of reversible shape memory effect in TiNi based materials], Dissertation thesis, VŠB Ostrava, 1997, 87.

[3] STÖCKEL, D.: Legierungn mit Formgedachtnis, München, (1988) p.197

[4] MENG, X.L., Scripta materialia, 45, 1177 (2001)

[5] MA, J. L., WU, K. H.: Materials science and technology, 16, 716 (2000).

[6] NOH, J.P. et al. Materials Science and Technology, 17, 1544 (2001)

[7] NAM, T.H. et al.Materials science and technology, 16, 1017 (2000).

[8] TSAI, J.CH. et al., Scripta Metallurgica et Materialia, 30, 1027 (1994).

[9] GRAHAM, R. et al.: SMST Society Inc., 2004, p. 7.

[10][DEMBOVSKÝ, V.: Plasma metallury: The principles, Materials science monographs, 23, SNTL, 1985, ISBN 0-444-99603-6.

[11]PACHOLEK, P., SZURMAN, I., SKLENAŘÍKOVÁ, I., KURSA, M.: Preparation specificity of shape memory alloys on the base of NiTi, $8^{\text {th }}$ International conference Technology 2003, 2003, Bratislava, $p$. 38, ISBN 80-227-1935-8.

[12] WU, M.H.: Materials Science Forum, 394-395, 285 (2002).

[13]FRENZEL, J. et al., Journal of Alloys and Compounds, 385, 214 (2004)

[14]ZHONGHUA, Z. et al., Acta Materialia, 50, 3971 (2005)

[15] RAMAIAH, K.V. et al Processing of Ni-Ti Shape Memory Alloys, Smart materials structures and systems, July 2005, Bangalore India. 